Purpose Research to understand the dynamics of the air-inflated membrane structures is strongly required.

Methods We developed a child's femur impactor (figure 1) to measure the impact force on the femur when the child falls on the equipment and examined the dynamics of the play equipment.

Results We conducted drop experiments to measure the impact force applied to the femur when landing on the equipment in the situation that a single child fall from a high position. The experimental result indicates that the impact force in the case of a single fall is proportional to both the collision velocity and the weight. Second, we studied the characteristics of the play equipment when two or more people are jumping. The experiment using the impactor revealed the new finding that the propagation of the membrane tension generated by a jumping adult can cause a fracture of the femur bone of a child around the adult. The computer simulation also supports the findings (figure 2).

Significance This new finding suggests that a new safety standard for equipment consisting of air-inflated membrane structure is required especially regarding the weight and the number of adults playing with children.

\section{DEVELOPMENT OF RISK ASSESSMENT SYSTEM OF CHILD'S FEMUR AND FOREARM FRACTURE DUE TO AIR-FILLED PLAY EQUIPIMENT AND RECOMMENDATION REGARDING ITS SAFE USE}

doi:10.1136/injuryprev-2012-040580e.24

\footnotetext{
${ }^{1,2}{ }^{2}$ Tokoro*, ${ }^{2} Y$ Nishida, ${ }^{1,2} \mathrm{H}$ Mizoguchi, ${ }^{2,3} \mathrm{~T}$ Yamanaka. ${ }^{1}$ Tokyo University of Science, Japan; ${ }^{2}$ National Institute of Advanced Industrial Science and Technology, Japan; ${ }^{3}$ Ryokuen Children's Clinic, Japan
}

Background Recently, the number of injuries due to play equipment consisting of an air-inflated membrane has been rapidly increasing. For example, a child fractures his femur when he is jumping on the play equipment and an adult is also jumping around him.

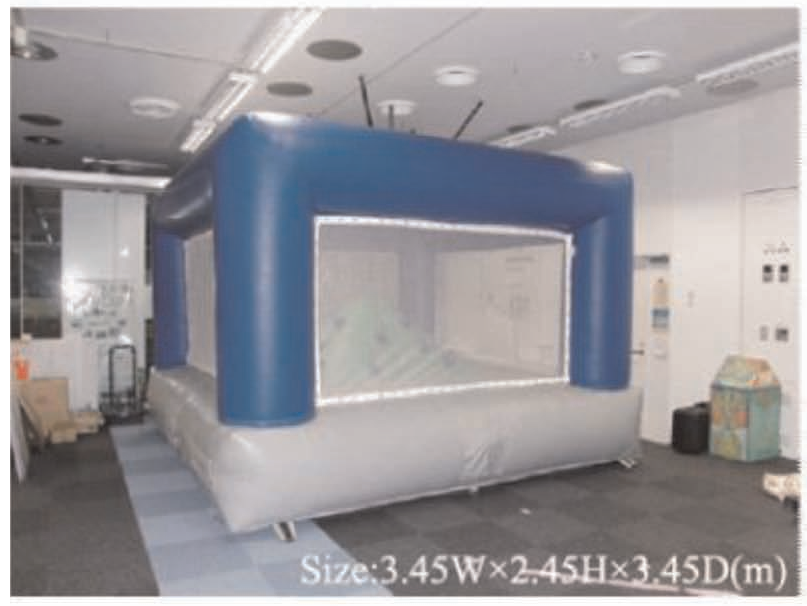

Figure 1 Play equipment and femur impactor.

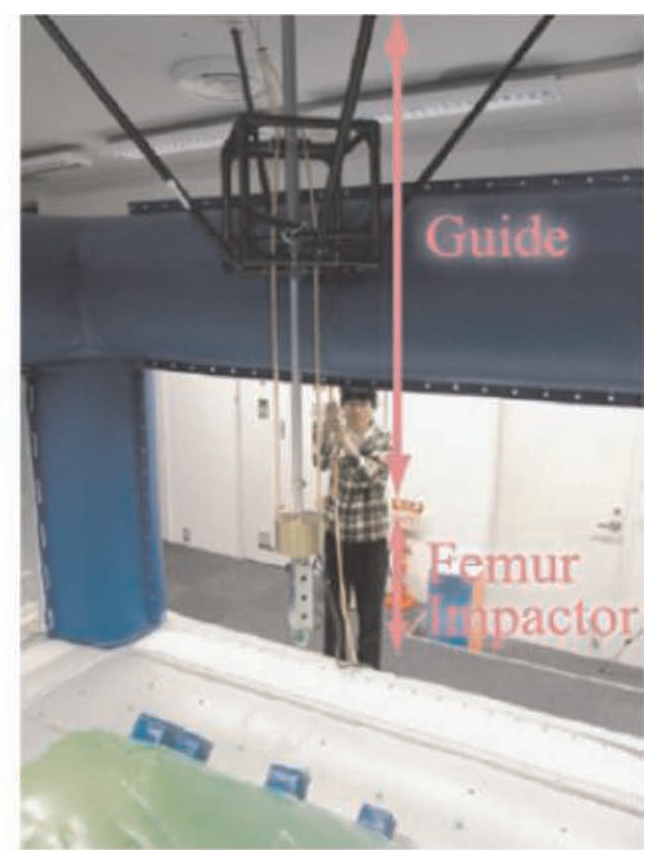




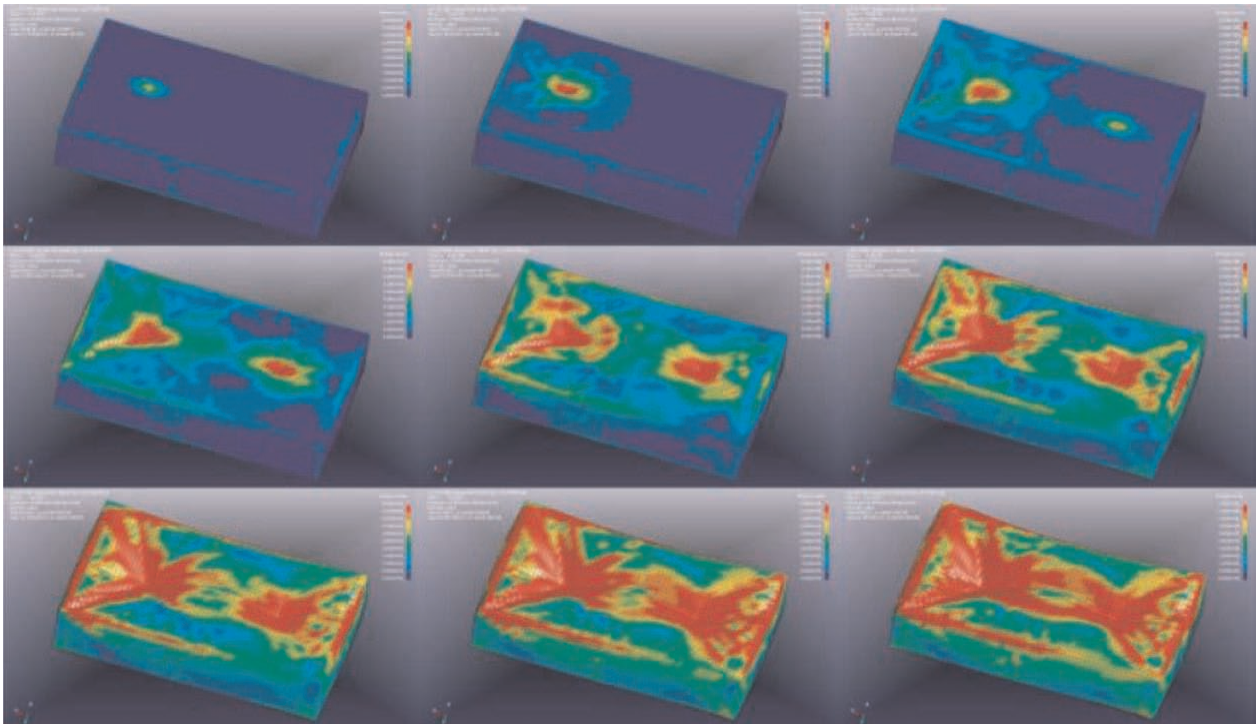

Figure 2 Computer simulation of propagation of impact. 